\title{
Unsafe Ingredients Included in Malaysian Food Drug Interphase (FDI) Products: Toyyiban perspective
}

\author{
Atiqah Aziz, Norkartini Abu Bakar, Zalina Zakaria \\ Universiti Malaya Pantai, Kuala Lumpur MALAYSIA. \\ *Corresponding Author Email: eyqa@um.edu.my
}

Doi: 10.2478/mjhr-2020-0011

\section{Abstract:}

There are more than $24.1 \%$ of the world's population are Muslim. Considering the religious preference, Drug Control Authority (DCA) requires manufacturers to declare clearly if their products contain materials of animal origin, as well as unsafe drugs. In general, Health supplements, herbal products, and traditional medicine are classified as "food-drug interphase (FDI) products. FDI products are products with a combination of food ingredients and active ingredients for oral consumption. FDI products are widely believed to be able to prevent or even cure many diseases. However, over the past ten years, there are various FDI products in Malaysia contain dangerous drugs. Hence, this study summarizes the harmful effect of listed unsafe drugs possess in the FDI products, the category of the product, and the type of claim. According to the National Pharmaceutical Regulatory Agency (NPRA) recent report, there are 162 FDI products have been mixed up with illegal drugs which majority of them contain Dexamethasone. The most category of products that contain unsafe drugs is among traditional medicine products followed by health supplements, herbal supplement products, and dietary supplements. These products were commonly marketed to strengthen the veins \& joint and pain relief, weight loss, sexual enhancement, energy booster, relieve sinus, and gout. Hence, an awareness of adulteration in pharmaceuticals is crucial to ensure the quality, safety, and effectiveness of the products towards human health.

Keywords: pharmaceutical, adulteration, herbal, traditional medicine, health supplement, drug, toyyiban, halal

\subsection{Introduction:}

The Muslim population is approaching 1.6 billion people and expected to be increased by $30 \%$ of the world's population by 2025 . There are around 1.3 billion Muslims in the world and 1.5 billion Halal consumers which is one out of every four human beings consume Halal products [1]. Halal is an Islamic term that guides the Muslims that what is allowed and prohibited for them to practice in every aspect of life which also includes any products allowed to be consumed and used by Muslims according to Syariah Law [2]. The concept of Halal is not only limited to food but it is also practiced in each aspect of Muslims' life such as pharmaceutical and cosmetics. As stated in the Holy Quran, "And spend in the way of Allah and do not throw (yourselves) with your (own) hands into destruction (by refraining). And do good; indeed, Allah loves the doers of good "Quran 2:195 [3]. "Forbidden to you (for food) are AlMaitah (the dead animals - cattle - beast not slaughtered), blood, the flesh of swine" (Sûrat Al-Mâ'idah, Verse 3).

In Malaysia, the concept of halal is meaningful for both Muslim and non-Muslim customers as consumers nowadays believe in the advantages that are associated with halal products. In other words, the religious and safety concept associated with the halal product has influenced the customers to purchase it [4]. Halal certification on non-food products (pharmaceutical, cosmetic, leather goods, and others) able to give Malaysia a unique edge globally to confirm the highest qualities of those products by counting religious aspects of fulfilling Muslim's obligations and business perspectives [5]. Moreover, Halal pharmaceutical products are suitable for both Muslims as well as non-Muslim consumers in terms of the knowledge of ingredient, process, and nature of the products.

The detection of adulterants is one of the greatest challenges facing not only in food and feed products companies but as well as cosmetics and pharmaceutical companies today. Therefore, this study was conducted to determine the most common adulterant detected in Malaysian FDI products based on the recent report by the National Pharmacy Adverse Impact Monitoring unit, National Pharmacy Regulatory Agency (NPRA) on 13th January 2017, to summarize the category of products and types of claims among the reported FDI products and to highlight the severity and danger of using such adulterated medication. All of the sample data in an Excel file from the recent report by the National Pharmacy Adverse Impact Monitoring unit, National Pharmacy Regulatory Agency (NPRA) was measured by Excel software.

An amazing array of food supplements have become available in the market around the world, including Malaysia. These products have been known by a variety of names, including "functional foods", "designer foods", nutraceuticals, nutrient supplements, and "health foods". Some of these products are not clearly defined as "food" or "drugs" but are freely marketed. Some of them are regulated as foods in some countries, while other countries may regulate them as drugs. A few countries group name them separately. Generally, health supplements, herbal products, and traditional medicine are classified as "food-drug interphase (FDI) products. FDI products are products with a combination of food ingredients and active ingredients for oral consumption. Food ingredients should include fruit, vegetables, meat, poultry, milk, cocoa, and cereal. Examples of active ingredients are vitamins, minerals, herbs, enzymes, probiotics, prebiotics, amino acids, peptides, coral calcium, fatty acids, collagen, chia seed, astaxanthin, lutein and other ingredients that are not traditionally consumed as food. FDI products are not presently considered to be part of conventional medicine [1].

FDI products are widely believed to be able to prevent or even cure many diseases including cancer. Some of the FDI products in Malaysia, there is scientific evidence that a treatment is both beneficial and safe. Unfortunately, many other products, the evidence is negative, lacking, or inconclusive. Statements that manufacturers and providers of FDI products may make about the effectiveness of a therapy and its other benefits can sound reasonable and promising. However, they may or may not be backed up by scientific evidence. Even though these products may not do as they claim, they may remain on the market as long as they are not shown or reported to be dangerous. FDI products may cause adverse reactions, just like prescription drugs can. The short- and longterm effects of these products are still unknown [2-4]. As well as FDI products could cure chronic diseases, these products also potentially trigger a serious health problem too [5-7]. Although the Halal cosmetic industry is large, not all products that are appeared to be Halal have been properly tested and examined in the laboratory. Some products manage to manipulate the existing Halal standard set in a particular country or even escape the stringent Halal procedures. Ironically, consumers also often overlook the ingredients or contents in the FDI products that may contain harmful chemicals.

In Malaysia, FDI products are not fully regulated like prescription medicines are, as these products can be sold without adequate safety testing, and without evidence that they produce the desired results [8]. Therefore, Food Safety and Quality Division (FSQD) of the Ministry of Health Malaysia and National Pharmacy Regulatory Agency (NPRA) have formed a Committee for the Classification of Food Drug Interphase Products in 2000 to assist both Divisions in classifying, in a consistent manner, an application from the industry which is not clearly defined either as a food or drug product [1]. 
As part of its function to monitor supplement safety, the National Pharmacy Adverse Impact Monitoring unit, National Pharmacy Regulatory Agency (NPRA), Malaysia, has received a side-effects report on the 162 FDI products in Malaysia and the results of the test have found that these products have been mixed up with undeclared adulterant (illegal drug) or scheduled poisons. Over 162 FDI products, $51 \%$ contain Dexamethasone, $25 \%$ of Chlorpheniramine, $7 \%$ of Sibutramine and the rest contain Tadalafil, Sildenafil, Phenylbutazone, and Caffeine [9].

\section{List of Adulterant in Malaysian FDI products}

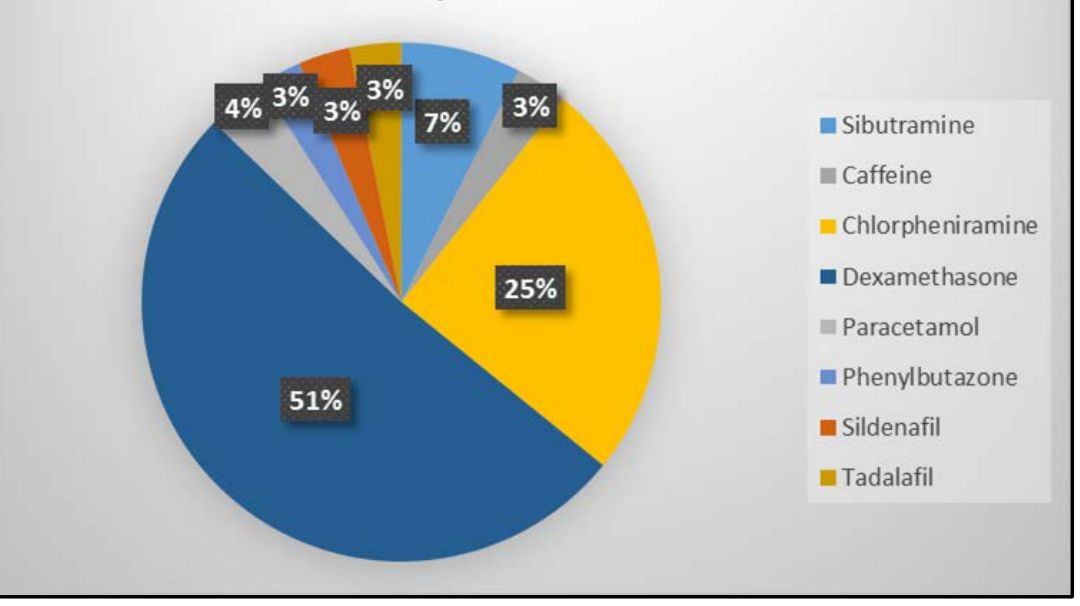

Materials used in FDI products must be suitable with Islamic philosophy which referring to given categories i.e contain substances from animals that are not halal or not slaughtered according to Islamic law, contain substances which are considered najis by Islamic law, unsafe and toxic, would cause damage or toxication and harmful to health, not prepared, processed or manufactured using equipment contaminated with najis according to Islamic law and contain human body parts or products which are not allowed by Islamic law [10-15]. Muslims are permitted to consume foods that not only be free from haram constituents but also good or termed Halalan Thoyyiban so that it would not jeopardize our body. Ministry of Health Malaysia (MOH) through the Pharmaceutical Services Division plays a role in ensuring medicines and FDI products in Malaysia are registered with MOH. Registered products will be evaluated in terms of safety and quality. This coincides with Thoyyiban concept [16-17]. In Malaysia, the Department of Islamic Development Malaysia (JAKIM) and State Islamic Department (JAIN) are the authority bodies that are responsible for halal pharmaceutical [15]. JAKIM plays an important role in introducing halal certification for pharmaceutical products based on the first Halal Pharmaceuticals Standard in the world which is the MS2424:2012 [18].

\subsection{List of Unsafe Drugs In Malaysian FDI Products}

\subsection{Dexamethasone}

Dexamethasone is a steroid that prevents the release of substances in the body that cause inflammation [10]. Dexamethasone works by mimicking the effect of cortisol, a hormone released by the adrenal glands (which are located on top of the kidneys) that controls metabolism and stress. Dexamethasone belongs to the class of medicines known as corticosteroids. It is specifically a glucocorticoid. Dexamethasone is used to treat many different conditions such as allergic disorders, skin conditions, ulcerative colitis, arthritis, lupus, psoriasis, or breathing disorders [11-12]. The following side effects are commonly occurring in greater than $30 \%$ for patients taking dexamethasone such as increased appetite, irritability, difficulty sleeping (insomnia), swelling in your ankles and feet (fluid retention), heartburn, muscle weakness, impaired wound healing and increased blood sugar levels [13-14].

\subsection{Chlorpheniramine}

Chlorpheniramine is the first-generation antihistamine used to relieve symptoms of allergy, hay fever, and the common cold but will not treat the cause of the symptoms or speed recovery [19]. These symptoms include rash, watery eyes, itchy eyes/nose/throat/skin, cough, runny nose, and sneezing. This medication works by blocking a certain natural substance (histamine) that your body makes during an allergic reaction [20-21]. By blocking another natural substance made by your body (acetylcholine), it helps dry up some body fluids to relieve symptoms such as watery eyes and runny nose. Common side effects may include drowsiness, dry mouth, nose, and throat, nausea, vomiting, loss of appetite, constipation, headache, increased chest congestion [22,23]. Some side effects can be serious which including vision problems and difficult urination.

\subsection{Sibutramine}

Sibutramine is indicated for the management of obesity, including weight loss and maintenance of weight loss, and should be used in conjunction with a reduced-calorie diet $[24,25]$. Sibutramine assists with weight-loss by altering neurotransmitters within the brain [26]. Neurotransmitters are produced and released by nerves to connect with other nerves. Released neurotransmitters may attach to other nerves or they may be taken up again by the nerves that release them. This process is called reuptake. Sibutramine blocks the reuptake of the neurotransmitters dopamine, norepinephrine, and serotonin. Blocking the reuptake of neurotransmitters alters the balance of neurotransmitters within the nerve cells and thereby affect nerve function and interaction $[27,28]$. In general, sibutramine is well-tolerated. The most common side effects have been constipation, inability to sleep, headache, dry mouth, abdominal pain, acne, rash, and chest pain. On a serious note, this ingredient was banned in many countries including the U.S. market in October 2010 and the Malaysian market in early 2017 due to toxicities and mortality effect such an increased risk of heart attack and stroke among those taking the obesity drug [29,30].

\subsection{Tadalafil}

Tadalafil is used to treat erectile dysfunction (inability to get or keep an erection) and symptoms of benign prostatic hypertrophy (enlarged prostate) which include difficulty urinating (hesitation, dribbling, weak stream, and incomplete bladder emptying), painful urination, and urinary frequency and urgency in adult men [31,32]. Moreover, it also used to improve the ability to exercise in people with pulmonary arterial hypertension (PAH; high blood pressure in the vessels carrying blood to the lungs, causing shortness of breath, dizziness, and tiredness) [33]. Tadalafil is in a class of medications called phosphodiesterase (PDE) inhibitors. It works to treat erectile dysfunction by increasing blood flow to the penis during sexual stimulation [34]. This increased blood flow can cause an erection. Tadalafil treats PAH by relaxing the blood vessels in the lungs to allow blood to flow more easily [35]. The side effects of Tadalafil are headache, indigestion or heartburn, nausea, diarrhea, flushing, pain in the stomach, back, muscles, arms, and cough [36]. Some side effects can be serious too, for example, getting sudden decrease or loss of vision, blurred vision, changes in color vision (seeing a blue tinge on objects or 
having difficulty telling the difference between blue and green), a sudden decrease or loss of hearing, ringing in ears and erection that lasts longer than 4 hours [37, 38].

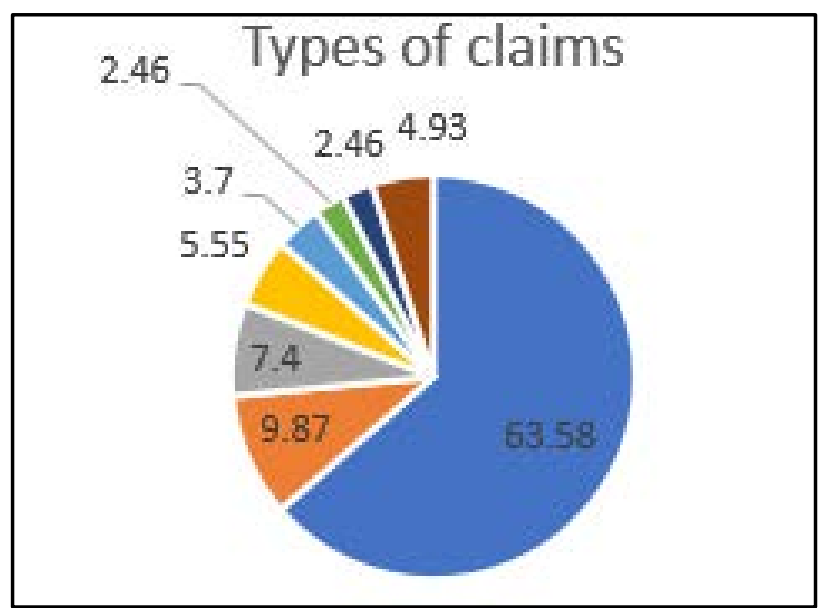

\section{- Pain relief}

= Relieve sinus

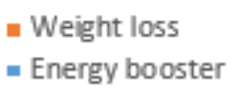

\subsection{Sildenafil}

This ingredient is a medication for male sexual function problems (impotence or erectile dysfunction-ED and commonly is used to treat pulmonary arterial hypertension and improve exercise capacity in men and women [39,40]. Sildenafil is a phosphodiesterase-5 (PDE5) inhibitor. PDE5 is a substance produced in the lungs and other parts of the body that breaks down another substance called cyclic guanosine monophosphate (GMP). Cyclic GMP causes the blood vessels (arteries) to relax and widen. In sexual function problem condition, Sildenafil inhibiting phosphodiesterase type 5 and allows corpus cavernosum smooth muscle to relax, potentiating erections during sexual stimulation [41]. Meanwhile, in hypertension condition, sildenafil decreases the activity of PDE5, so that more cyclic GMP is available for the blood vessels inside the lungs to decreases the pulmonary blood pressure to the heart and improves its function. Even though sildenafil is generally well tolerated, it still may lead to various side effects such as nose bleeds, headache, upset stomach and heartburn, worsening shortness of breath, and nasal congestion. Caution should be taken as sildenafil should not be used in combination with nitrates or nitric oxide donors as an unsafe drop in systemic blood pressure may occur [42,43].

Table. Category of product in 162 FDI products reported by the NPRA to be adulterated in Malaysia

\section{Category of Products}

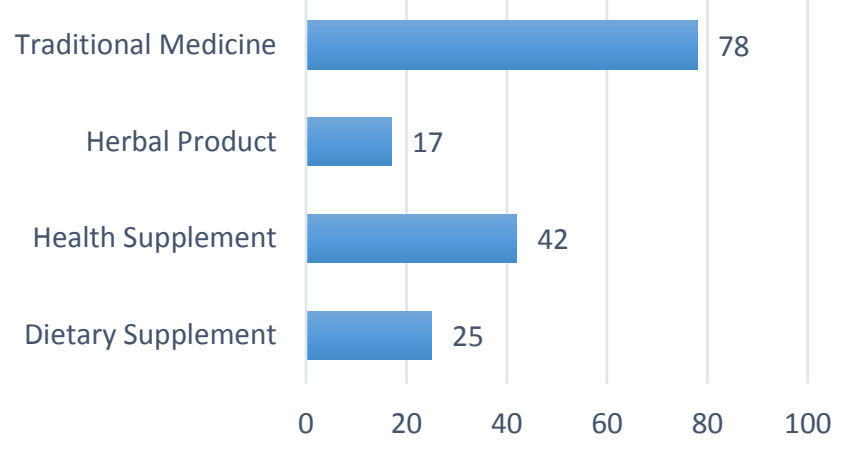

Abrreviation: NPRA, National Pharmaceutical Regulatory Agency (NPRA)

\subsection{Phenylbutazone}

Phenylbutazone is a nonsteroidal anti-inflammatory drug (NSAID) [44]. It also is known as a painkiller for horses, which can cause blood disorders in humans but at doses much higher than any one person is likely to ingest from eating horsemeat [45,46]. In the 1950s, the drug was used to treat inflammation and pain that results from rheumatoid arthritis, gout, and osteoarthritis [47]. But has been removed from the market in most countries due to the availability of newer drugs with less adverse effects. Its mechanism of action is by inhibiting the body's production of prostaglandins, thromboxane, and other inflammatory mediators. Some of these actions may be dose-dependent [48]. Phenylbutazone is not commonly used nowadays because of the unique potential for severe bone marrow toxicity, which results in dangerously low white blood cell counts, and these given phenylbutazone a bad reputation for safety [49]. Serious side effects can occur and generally tend to be dose-related. The most common side effects of phenylbutazone involve ulcerations, abdominal burning, pain, cramping, nausea, gastritis, serious gastrointestinal bleeding, and liver toxicity. Sometimes, stomach ulceration and bleeding can occur without any abdominal pain [50].

\subsection{Caffeine}

Caffeine is a psychoactive drug which consider being both a drug and a food additive [51]. This substance also an ingredient in some prescription and nonprescription drugs, such as cold, allergy, and pain medication [52]. An example of a medication that used caffeine as an ingredient is Aspirin and Cafcit/ Caffeine citrate (available by prescription only). According to Malaysia National Drug Policy 2017, caffeine is fallen under 10 different classes of drug and it refers to a drink or liquor containing an active ingredient of weakly stimulated xanthine contained particularly in energy drinks, coffee, tea, chocolate, or soft drinks [53]. Caffeine acts as a stimulant by activating the central nervous system (CNS). It can counteract tiredness and improve concentration and focus $[54,55]$. Ingesting caffeine in high doses may lead to more harmful effects on health. Several unwanted side effects of consuming more than $400 \mathrm{mg}$ of caffeine per day may lead to a fast heartbeat, anxiety, agitation, restlessness, sleeping problems, and tremors [56]. 


\subsection{Paracetamol}

The consumers mostly had taken paracetamol to treat fever, headache, menstrual pain, and common pain [57]. According to the Ministry of Health Medicines Formulary-2/2015 (Malaysia), the optimal dosage of paracetamol for adults is $500-1000 \mathrm{mg}$ every $4-6$ hours, a maximum of $4 \mathrm{~g}$ daily. Researchers have been guessing at paracetamol's mechanism of action for decades. Some explanations involve chemical messengers of inflammation and pain. Others invoke aspects of neurotransmission in the brain and spinal cord. But the exact mechanism of action is still not known. In Malaysia, consumers are able to treat minor illnesses themselves due to easy accessibility to over-the-counter drugs including paracetamol. However, self-medication using it without proper information and knowledge is dangerous as this might leads to acetaminophen overdose and poisoning. An overdose of paracetamol can cause serious harm. An acute single ingestion of acetaminophen dose $>10 \mathrm{~g}$ or $200 \mathrm{mg} / \mathrm{kg}$ (whichever is lower) in adults will lead to liver toxicity.

\subsection{Discussion}

In this quality improvement study, analysis of unsafe ingredients included in Malaysian FDI products showed that unapproved pharmaceutical ingredients were identified in 162 FDI products with the category of 78 traditional medicine products, 42 health supplement products, 17 herbal supplement products and 25 product of dietary supplement. These products were commonly marketed to strengthen the veins \& joint and pain relief, weight loss, sexual enhancement, energy booster, relieve sinus, and gout. The most common adulterants were Dexamethasone, a corticosteroid used to reduce inflammation, Sibutramine for weight loss supplements, and Chlorpheniramine for treating clinical symptoms. It is common in the halal market to use the terms halal and halal-toyyiban interchangeably due to a perception that whatever is halal, is also halalan-toyyiban. But, the two terms carry two different meanings. For example, junk food that complies with halal certification requirements is certified as halal. Such certification tells the world that these products do not contain items prohibited by the Syariah law while simultaneously complying with the specified legal provisions prescribed by the law of the land. But, although, they are certified as such, eating junk food is unhealthy and could lead to many health issues. This scenario was similar to consuming FDI products composed of unapproved ingredients. Even though these products using an organic or natural product which represent the halal aspect but with the contamination of adulterant, this product is no longer toyyib as it was harmful and unsafe. Since Malaysia aspires to become the global halal hub, it is time to extend the application of halalan-toyyiban to other areas in the halal industry as this would encourage the halal market players to produce products or services that are not only halal-certified but also contain wholesome elements. The aforementioned public regulation is vital for the protection of public health. Without the regulatory control and adequate law enforcement on the said product, members of the public would be at stake of health risks such as multi-organ failure and poisoning, including fatalities. This is in line with the toyyiban aspect which means any products, which are not harmful and safe to be consumed as underlined by the Syariah law, and thus are allowable and permissible.

\subsection{Conclusion}

The use of unsafe/undeclared drugs is prevalent among consumers. The drug ingredients in these FDI products have the potential to cause a serious adverse effect. The consumers found to have a lack of awareness of adulterant used in FDI products, lack of medical advice regarding the proper dosage, side effects of unsafe/undeclared drug used in those products, and interactions with other agents. The potential risk of adulterant overdose existed among the consumers is high. All these issues need to be addressed promptly in order to avoid poisoning among consumers. Furthermore, this investigation is not able to extend the application of halalan-toyyiban to other areas in the halal industry and raising halalan toyyiban awareness globally as this would encourage the halal market players to produce products that are not only halal-certified but also contain wholesome elements.

\subsection{References}

[1] B. Niggemann, C. Gruber, "National Pharmaceutical Regulatory Agency Ministry Of Health, Malaysia, Drug Registration Guidance Document (DRGD) Sideeffects of complementary and alternative medicine", Allergy, Vol. 58, No. 8, Pp. 707-716, 2003.

[2] I. Houssien, Small and medium enterprises and access to finance in Egypt, 2014.

[3] K. Hussain, M.T. Majeed, Z. Ismail, A. Sadikun, A. Ibrahim, "Traditional and complementary medicines: Quality assessment strategies and safe usage", Southern Med Review, Vol. 2, No. 1, Pp. 19-23, 2009.

[4] A. Palanisamy, C. Haller, K.R. Olson, "Photosensitivity reaction in a woman using an herbal supplement containing ginseng, goldenseal, and bee pollen", Journal of Toxicology: Clinical Toxicology, Vol. 41, No. 6, Pp. 865-867, 2003.

[5] A.I. Geller, N. Shehab, N.J. Weidle, M.C. Lovegrove, B.J. Wolpert, B.B. Timbo, D.S. Budnitz, "Emergency department visits for adverse events related to dietary supplements", New England Journal of Medicine, Vol. 373, No. 16, Pp. 1531-1540, 2015.

[6] Dietary supplement, Food Facts, U.S Food \& Drug Administration. Retrieved from https://www.fda.gov/downloads/Food/DietarySupplements/UCM240978.pdf

[7] P. Jayaraj, "Regulation of traditional and complementary medicinal products in Malaysia”, International Journal of Green Pharmacy, Vol. 4, No. 1, Pp. 10, 2010.

[8] E.O. Meltzer, G.D. Berman, J. Corren, A.J. Pedinoff, G. Doyle, J.A. Waksman, S. Wason, "Addition of ibuprofen to pseudoephedrine and chlorpheniramine in the treatment of seasonal allergic rhinitis", Annals of Allergy, Asthma \& Immunology, Vol. 93, No. 5, Pp. 452-459, 2004.

[9] N.K. Lariya, G.P. Agrawal, "Development and validation of RP-HPLC method for simultaneous determination of methotrexate, dexamethasone and indomethacin", International Journal of Pharmacy and Pharmaceutical Sciences, Vol. 7, No. 3, Pp. 443-446, 2014.

[10] M.E. Parsons, C.R. Ganellin, “Histamine and its receptors”, British journal of pharmacology, Vol. 147, No. S1, Pp. S127-S135, 2006.

[11] N.H. Waldron, C.A. Jones, T.J. Gan, T.K. Allen, A.S. Habib, "Impact of perioperative dexamethasone on postoperative analgesia and side-effects: systematic review and meta-analysis", British journal of anaesthesia, Vol. 110, No. 2, Pp. 191-200, 2012.

[12] M.S. Wong, "Pocket orthopaedics: evidence-based survival guide: evidence-based survival guide”, Jones \& Bartlett Publishers, 2009.

[13] Malaysian Standard. “Halal Pharmaceuticals general guidelines”, Malaysian Standard MS 2424, Department of Standards, Malaysia, 2010.

[14] A. Sarriff, "Exploring the halal status of cardiovascular, endocrine, and respiratory group of medications", The Malaysian journal of medical sciences: MJMS, Vol. 20, No. 1, Pp. 69, 2013.

[15] T.M. Khan, S. Shaharuddin, "Need for contents on halal medicines in pharmacy and medicine curriculum", Arch Pharm Pract., Vol. 6, Pp. 38-40, 2015.

[16] N. Noordin, N.L.M. Noor, Z. Samicho, "Strategic approach to halal certification system: An ecosystem perspective", Procedia-Social and Behavioral Sciences, Vol. 121, Pp. 79-95, 2014. 
[17] H. Suzuki, A. Shigeta, T. Fukunaga, “Accidental death of elderly persons under the influence of chlorpheniramine”, Legal Medicine, Vol. 15, No. 5, Pp. 253-255, 2013.

[18] M. Tagawa, M. Kano, N. Okamura, M. Higuchi, M. Matsuda, Y. Mizuki, T. Ido, "Neuroimaging of histamine H1-receptor occupancy in human brain by positron emission tomography (PET): a comparative study of ebastine, a second-generation antihistamine, and (+)-chlorpheniramine, a classical antihistamine", British journal of clinical pharmacology, Vol. 52, No. (5), Pp. 501-509, 2001. https://www.adk.gov.my/wp-content/uploads/BukuDasar-Dadah-Negara-EN.pdf

[19] A.C. Deslandes, H. Veiga, M. Cagy, R. Piedade, F. Pompeu, P. Ribeiro, "Effects of caffeine on the electrophysiological, cognitive and motor responses of the central nervous system", Brazilian Journal of Medical and Biological Research, Vol. 38, No. 7, Pp. 1077-1086, 2005.

[20] G. Fisone, A. Borgkvist, A. Usiello, “Caffeine as a psychomotor stimulant: mechanism of action”, Cellular and Molecular Life Sciences CMLS, Vol. 61, No. 7-8, Pp. 857-872, 2004.

[21] M.E.J. Lean, “How does sibutramine work?”, International Journal of Obesity \& Related Metabolic Disorders, Vol. 25, 2001.

[22] R.J. Araujo, F. Martel, "Sibutramine effects on central mechanisms regulating energy homeostasis", Current neuropharmacology, Vol. 10, No. 1, Pp. 49$52,2012$.

[23] E. Wooltorton, “Obesity drug sibutramine (Meridia): hypertension and cardiac arrhythmias”, Cmaj, Vol. 166, No. 10, Pp. 1307-1308, 2002.

[24] T.M. Saifuddin, N. Rahim, N.Z. Mansor, "Psychosis Associated with Weight-loss Product Containing Sibutramine: A Case Report", Malaysian Journal of Psychiatry, Vol. 26, No. 2, Pp. 53-56, 2018.

[25] F. Montorsi, H.P. Nathan, A. Mccullough, G.B. Brock, G. Broderick, S. Ahuja, L. Varanese, "Tadalafil in the treatment of erectile dysfunction following bilateral nerve sparing radical retropubic prostatectomy: a randomized, double-blind, placebo controlled trial", The Journal of urology, Vol. 172, No. 3, Pp. 1036-1041, 2004.

[26] H. Porst, H. Padma-Nathan, F. Giuliano, G. Anglin, L. Varanese, R. Rosen, "Efficacy of tadalafil for the treatment of erectile dysfunction at 24 and 36 hours after dosing: a randomized controlled trial”, Urology, Vol. 62, No. 1, Pp. 121-125, 2003.

[27] S. Takatsuki, M. Calderbank, D.D. Ivy, “Initial experience with tadalafil in pediatric pulmonary arterial hypertension”, Pediatric cardiology, Vol. 33, No. 5, Pp. 683-688, 2012.

[28] J.M. McKoy, C.R. Bolden, A. Samaras, D.W. Raisch, K. Chandler, C.L. Bennett, "Sildenafil-and tadalafil-associated optic neuropathy: implications for men after prostate cancer treatment", Community oncology, Vol. 6, No. 2, Pp. 78, 2009.

[29] N. Galiè, B.H. Brundage, H.A. Ghofrani, R.J. Oudiz, G. Simonneau, Z. Safdar, L. Frumkin, "Tadalafil therapy for pulmonary arterial hypertension", Circulation, Vol. 119, No. 22, Pp. 2894, 2009.

[30] K.K. Gaines, "For Erectile Dysfunction”, Urologic nursing, Vol. 24, No. 1, 2004.

[31] R. Gazzeri, M. Neroni, M. Galarza, S. Esposito, “Intracerebral hemorrhage associated with use of tadalafil (Cialis)”, Neurology, Vol. 70, No. 15, Pp. 12891290.

[32] A.S. Khan, Z. Sheikh, S. Khan, R. Dwivedi, E. Benjamin, "Viagra deafness-Sensorineural hearing loss and phosphodiesterase-5 inhibitors", The Laryngoscope, Vol. 121, No. 5, Pp. 1049-1054, 2011.

[33] L. Becker, B. Eberlein-König, B. Przybilla, "Phototoxicity of non-steroidal anti-inflammatory drugs: in vitro studies with visible light", Acta dermatovenereologica, Vol. 76, No. 5, Pp. 337-340, 1996.

[34] D.J. Gordon, U.S. Patent No. 6,022,563. Washington, DC: U.S. Patent and Trademark Office, 2000.

[35] P.J. Neuvonen, E. Elonen, "Effect of activated charcoal on absorption and elimination of phenobarbitone, carbamazepine and phenylbutazone in man", European Journal of Clinical Pharmacology, Vol. 17, No. 1, Pp. 51-57, 1980.

[36] E.G. Boyce, E.M. Umland, “Sildenafil citrate: a therapeutic update”, Clinical therapeutics, Vol. 23, No. 1, Pp. 2-23, 2001.

[37] S.G. Swearingen, J.D. Klausner, "Sildenafil use, sexual risk behavior, and risk for sexually transmitted diseases, including HIV infection", The American journal of medicine, Vol. 118, No. 6, Pp. 571-577, 2005.

[38] I.S. De Tejada, J. Angulo, P. Cuevas, A. Fernandez, I. Moncada, A. Allona, E. Pages, "The phosphodiesterase inhibitory selectivity and the in vitro and in vivo potency of the new PDE5 inhibitor vardenafil”, International journal of impotence research, Vol. 13, No. 5, Pp. 282-290, 2001.

[39] C. Kruuse, L.L. Thomsen, T.B. Jacobsen, J. Olesen, "The phosphodiesterase 5 inhibitor sildenafil has no effect on cerebral blood flow or blood velocity, but nevertheless induces headache in healthy subjects", Journal of Cerebral Blood Flow \& Metabolism, Vol. 22, No. 9, Pp. 1124-1131, 2002.

[40] P.P. Khanna, H.S. Gladue, M.K. Singh, J.D. FitzGerald, S. Bae, S. Prakash, R. Terkeltaub, "Treatment of acute gout: a systematic review", In Seminars in arthritis and rheumatism, Vol. 44, No. 1, Pp. 31-38, 2014.

[41] C. Rohde, D.E. Anderson, A.L. Bertone, S.E. Weisbrode, S. E. "Effects of phenylbutazone on bone activity and formation in horses", American Journal of Veterinary Research, Vol. 61, No. 5, Pp. 537-543, 2000.

[42] N. Dodman, N. Blondeau, A.M. Marini, "Association of phenylbutazone usage with horses bought for slaughter: a public health risk", Food and chemical toxicology, Vol. 48, No. 5, Pp. 1270-1274, 2010.

[43] J.R. Martínez Aranzales, B.S. Cândido de Andrade, G.E. Silveira Alves, "Orally administered phenylbutazone causes oxidative stress in the equine gastric mucosa", Journal of veterinary pharmacology and therapeutics, Vol. 38, No. 3, Pp. 257-264, 2015.

[44] A.K. Rötting, D.E. Freeman, P.D. Constable, J.A.C. Eurell, M.A. Wallig, "Effects of phenylbutazone, indomethacin, prostaglandin E2, butyrate, and glutamine on restitution of oxidant-injured right dorsal colon of horses in vitro", American journal of veterinary research, Vol. 65, No. 11, Pp. 15891595,2004 .

[45] J.L. Baldwin, R. Storb, E.D. Thomas, M. Mannik, "Bone marrow transplantation in patients with gold-induced marrow aplasia”, Arthritis \& Rheumatism: Official Journal of the American College of Rheumatology, Vol. 20, No. 5, Pp. 1043-1048, 1977. 
[46] J.R. Martínez Aranzales, B.S. Cândido de Andrade, G.E. Silveira Alves, "Orally administered phenylbutazone causes oxidative stress in the equine gastric mucosa", Journal of veterinary pharmacology and therapeutics, Vol. 38, No. 3, Pp. 257-264, 2015.

[47] K.L. Durrant, "Known and hidden sources of caffeine in drug, food, and natural products", Journal of the American Pharmaceutical Association, Vol. 42, No. 4, Pp. 625-637, 2002.

[48] V.G. Lizogub, D.S. Riley, M. Heger, "Efficacy of a pelargonium sidoides preparation in patients with the common cold: a randomized, double blind, placebo-controlled clinical trial", EXPLORE: the Journal of Science and Healing, Vol. 3, No. 6, Pp. 573-584, 2007. Retrived from https://www.adk.gov.my/wp-content/uploads/Buku-Dasar-Dadah-Negara-EN.pdf

[49] C.J. Sinclair, J.D. Geiger, “Caffeine use in sports”, A pharmacological review. J Sports Med Phys Fitness, Vol. 40, No. 1, Pp. 71-79, 2000.

[50] S. Cappelletti, P. Daria, G. Sani, M. Aromatario, "Caffeine: cognitive and physical performance enhancer or psychoactive drug", Current neuropharmacology, Vol. 13, No. 1, Pp. 71-88, 2015.

[51] M.A. Hassali, A.H. Mohamad Yahaya, A.A. Shafie, F. Saleem, G.N. Chua, H. Aljadhey, "Patterns and predictors of nonprescription medicine use among Malaysian pharmacy patrons: A national cross sectional study”, PLoS One, 8:e59231, 2013.

[52] C.P. Chong, S.F. Tan, W.T. Chooi, "An Evaluation on Consumers' Usage Pattern of Acetaminophen (Paracetamol): A Multicenter Study from Penang, Malaysia", Archives of Pharmacy Practice, Vol. 8, No. 1, 2017. Retrived from https://www.pharmacy.gov.my/v2/sites/default/files/documentupload/pfukkm-2-2015-jun.pdf

[53] R.C. Dart, A.R. Erdman, K.R. Olson, G. Christianson, A.S. Manoguerra, P.A. Chyka, "Acetaminophen poisoning: An evidence-based consensus guideline for out of hospital management”, Clin Toxicol (Phila)., Vol. 44, No. 1, Pp. 18, 2006.

[54] A.M. Larson, "Acetaminophen hepatotoxicity", Clinics in liver disease, Vol. 11, No. 3, Pp. 525-548, 2007.

[55] A, Abdullah, "Difference between Halal and Halalan-Toyyiban", International Institute of Advanced Islamic Studies (IAIS) Malaysia https://www.nst.com.my/opinion/columnists/2018/04/357046/difference-between-halaland-halalan-toyyiban, 2018.

[56] J.R. Mora, M. Iwata, U.H. Von Andrian, "Vitamin effects on the immune system: vitamins A and D take centre stage", Nature Reviews Immunology, Vol. 8, No. 9, Pp. 685, 2008.

[57] E.N. Omar, H.S. Jaafar, M.R. Osman, F. Nasruddin, Halalan Toyyiban supply chain the new insights in sustainable supply chain management, 2013. 